Article

\title{
Analysis of Land Use and Land Cover Change Using Time-Series Data and Random Forest in North Korea
}

\author{
Yong Piao ${ }^{1}\left(\mathbb{D}\right.$, Seunggyu Jeong ${ }^{2, *}$, Sangjin Park ${ }^{3}(\mathbb{D})$ and Dongkun Lee ${ }^{1,4}(\mathbb{D}$ \\ 1 Research Institute of Agriculture Life Science, Seoul National University, Seoul 08826, Korea; \\ topdyd@snu.ac.kr (Y.P.); dklee7@snu.ac.kr (D.L.) \\ 2 Animal Resources Division, National Institute of Biological Resources, Incheon 22689, Korea \\ 3 Interdisciplinary Program in Landscape Architecture \& Transdisciplinary Program in Smart City Global \\ Convergence, Seoul National University, Seoul 08826, Korea; parkssang87@snu.ac.kr \\ 4 Department of Landscape Architecture and Rural System Engineering, Seoul National University, \\ Seoul 08826, Korea \\ * Correspondence: rsgis@korea.kr; Tel.: +82-32-590-7410; Fax: +82-32-590-7417
}

Citation: Piao, Y.; Jeong, S.; Park, S.; Lee, D. Analysis of Land Use and Land Cover Change Using TimeSeries Data and Random Forest in North Korea. Remote Sens. 2021, 13, 3501. https://doi.org/10.3390/ rs13173501

Academic Editors: Parth Sarathi Roy and Giuseppe Modica

Received: 18 June 2021

Accepted: 31 August 2021

Published: 3 September 2021

Publisher's Note: MDPI stays neutral with regard to jurisdictional claims in published maps and institutional affiliations.

Copyright: (c) 2021 by the authors. Licensee MDPI, Basel, Switzerland. This article is an open access article distributed under the terms and conditions of the Creative Commons Attribution (CC BY) license (https:/ / creativecommons.org/licenses/by/ $4.0 /)$.

\begin{abstract}
North Korea being one of the most degraded forests globally has recently been emphasizing in forest restoration. Monitoring the trend of forest restoration in North Korea has important reference significance for regional environmental management and ecological security. Thus, this study constructed and analyzed a time-series land use land cover (LULC) map to identify the LULC changes (LULCCs) over extensive periods across North Korea and understand the forest change trends. The analysis of LULC used Landsat multi-temporal image and Random Forest algorithm on Google Earth Engine(GEE) from 2001 to 2018 in North Korea. Through the LULCC detection technique and consideration of the cropland change relation with elevation, the forest change in North Korea for 2001-2018 was evaluated. We extended the existing sampling methodology and obtained a higher overall accuracy $(98.2 \% \pm 1.6 \%)$, with corresponding kappa coefficients $(0.959 \pm 0.037)$, and improved the classification accuracy in cropland and forest cover. Through the change detection and spatial analysis, our research shows that the forests in the southern and central regions of North Korea are undergoing restoration. The sampling method we extended in this study can effectively and reliably monitoring the change trend of North Korea forests. It also provides an important reference for the regional environmental management and ecological security in North Korea.
\end{abstract}

Keywords: forest change trend; terrace field; North Korea; random forest (RF); Google Earth Engine (GEE)

\section{Introduction}

Forests cover approximately one-third of the Earth's land area but account for about two-thirds of the Earth's total photosynthesis; they have an extremely large exchange with the atmosphere and are sensitive to climate change and human activities [1]. Forests provide vital organic infrastructure for the planet such as climate control, disaster prevention, and carbon balance. Human activities, such as deforestation, land use, land-use change, and logging, affect changes in carbon stocks between the carbon pools of the terrestrial ecosystem and the atmosphere [2]. The detection of changes in the magnitude of land use land cover (LULC) by deforestation can help solve the current greenhouse gas emissions problem. Further, protecting and restoring forests could play a crucial role in the solution $[3,4]$.

North Korea (the Democratic People's Republic of Korea (DPRK) is known to have some of the most degraded forests in the world, converted to croplands of terrace field from mountainous areas, approximately $80 \%$ of North Korea's terrain [5]. The terrace field is one of the characteristic North Korea cropland types. Remote sensing can be used for detecting LULC changes of a dynamic landscape at large spatial and temporal scales. 
Several researchers have been using remote sensing techniques for studying LULC to identify crop and forest cover changes in North Korea [5-9].

Single-year satellite image data [5] uses traditional methods to focus on producing LULC maps rather than on analyzing trends [6]. Further, sensors with low spatial resolution (such as, MODIS) [5,6] might not provide accurate results at a large spatial and temporal scale for monitoring change at the macro level because North Korea has high land-cover heterogeneity and fragmented forest patches due to deforestation [6]. Some previous studies have used an LULC dataset based on unsupervised classification methods that were provided by South Korea's Ministry of Environment (MOE) [7-9]. This dataset has a classification accuracy of above 70\% for North Korea [8]. However, the low resolution or low accuracy of LULC data restricts the analysis of LULC changes in North Korea such as the transfer of terrace field and forests.

In the LULC supervision classification, there are generally three sampling methods: on-site investigation, visual interpretation, and referencing existing LULC products. For example, Jin et al. conducted on-site surveys and collected sample points for LULC classification [6]. Another study used google earth high-resolution images with a visual interpretation of the main land cover categories to construct sample points [10]. Rodriguez-Galiano et al. referenced existing LULC products (Andalusian land-cover maps) to construct sample points [11]. However, the above three methods are generally limited by the influence of manpower, time, and large areas.

Previous studies have focused on the overlay of multiple existing LULC products, filtered and selected points (or polygon) with consistent attributes, such as sample points (or polygon) [12-14]. This ensured that the sampling area is not limited by manpower, time, and large areas. However, these approaches are limited in their capacity to improve small patch classification (such as built-up areas, cropland etc.) at large scales because of heterogeneity and lack of geographic integrity of samples [15]. As some of the selected existing LULC products exhibit coarse resolutions $(>250 \mathrm{~m}$ ), there is uncertainty regarding the precise location and accuracy of small patches such as built-up areas or cropland. North Korea has complex terrains and landcover types that vary in size [6]. This may lead to differences in the pixel scales of different land cover types in high-resolution images (Landsat). Due to the mountainous terrain in North Korea, terrace fields are among the main cropland types [5]. The existing terrace field area ranges from a large range of mountain reclamation areas (a small part of the Landsat image) to the size of several Landsat patches. They need to be high enough and exhibit consistent resolution to be filtered and included in the cropland type. From the perspective of remote sensing, each land type analyzed in this study was a piece of land with a minimum of $30 \mathrm{~m} \times 30 \mathrm{~m}$ pixels ( $30 \mathrm{~m}$ resolution). Referencing existing products of different resolution is likely to lead to uncertainty in homogeneity and geographic integrity of the sample [15]. Therefore, the existing LULC products must be selected based on the characteristics of the research area. For example, Globcover2009 is excluded due to visual interpretation errors in the research area.

Remote sensing combining classification algorithms and indices obtained from multitemporal data makes it possible to reduce uncertainties associated with LULC changes in inaccessible areas. Previous studies have been widely applied to LULC, using multitemporal data including a variety of data, indices, and algorithms of classification in deforestation regions [16-18]. However, large uncertainties arise due to variations among the land use change processes that stem from a lack of consistent long-term monitoring measurements at regional scales [12].Classification algorithms, such as ISODATA and K-Means, have more limitations, such as over-fitting, high collinearity, high sensitivity to outliers, high dimensionality, and large noise, than machine learning and ensemble algorithms (MLEA) [19,20]. The advantage of MLEA is its non-parametric approach based on non-linear data, such as Random Forest (RF) based on machine learning, support vector machines, K-nearest neighbor, artificial neural network, and classification and regression tree. Additionally, MLEA can improve classification accuracy by reducing collinearity 
and noise processing of time-series data without overfitting. In particular, RF combined with phenological information provides better classification accuracy of cropland and semi-arid vegetation than other MLEAs as it captures specific seasonal patterns of each landscape type [6,21-23]. However, there is still insufficient information to identify LULC change reflected forest phenology of growing season and improver landcover mapping during long time-periods because it is difficult to collect cloud-free data resolution set [12] at a macro level during rainy season and apply suitable indices and algorithms [24]. In particular, collecting data from long time series at a macro scale for LULC in a large-scale area has some limitations because of the extensive resource requirement such as manpower, time, and big data processing.

Google Earth Engine (GEE) has been widely used in many LULC studies [25] and has achieved excellent results because GEE can solve the most important problems related to large-scale LULC mapping [26,27]. As a cloud computing platform, GEE not only easily accesses and quickly processes large amounts of data, but also does not need to download the required data to a local machine [28]. The availability of many algorithms in GEE and a data catalog that can access multiple satellite data and products make it easy for researchers to access and use remote sensing tools [28]. This makes it possible to use its huge image catalog to construct long-term sequence data and analyze trends in long-term change generated by it. Such temporal aggregation methods (mean, median) in GEE greatly reduce cloud interference, and can easily build long-time series of satellite image data [26,29]. This solves the problems of cloud interference during monsoons and the inability to use satellite image data for certain time periods [30]. In addition, different composition methods for generating time series data and different input images have varying effects on the classification results. Existing studies have shown that temporal aggregation methods are better than methods involving selection of only cloudless images [26]. On the composition of time series, the season of maximum potential vegetation activity (summer set) [26] and the composition of the period three years before and after the time period, were found to have better quality performance [15,31].

In summary, North Korea is located in the North of the Korean Peninsula in Northeast Asia. June-August is the main plant growing season and is also the rainy season. The entire area to cover to be covered is 23 Landsat tiles and a cloudless synthesis of approximately 2484 images is required for the image (2001-2018, combined images from June to August). Therefore, GEE is among the best options for mapping long-term LULC in North Korea.

The purpose of this study is to extend the existing sampling method to improve classification accuracy. We used time series Landsat data and applied RF with GEE platform to classify the LULC between 2001 and 2018 in North Korea. It also aimed to identify LULC changes to reveal trends in changes in North Korean forests, construct LULC data for inaccessible areas in North Korea, and investigate the relationship between terrace fields and elevation.

\section{Study Area}

North Korea is located in the northern part of the Korean peninsula in East Asia, accounting for $55.1 \%$ of the total area of the Korean peninsula and covers nine districts and counties. More than $80 \%$ of North Korea's land is mountainous and is primarily concentrated in the north (Figure 1). The height of the mountains in the region gradually decreases from north to south, creating plains and croplands in the southern and western regions. North Korea has a temperate monsoon climate, with an average annual temperature of 8-12 ${ }^{\circ} \mathrm{C}$ and an annual rainfall of $600-1000 \mathrm{~mm}$ [32]. The rainy season is concentrated in the summer, from July to August, and the dry season occurs in spring, from April to May. 


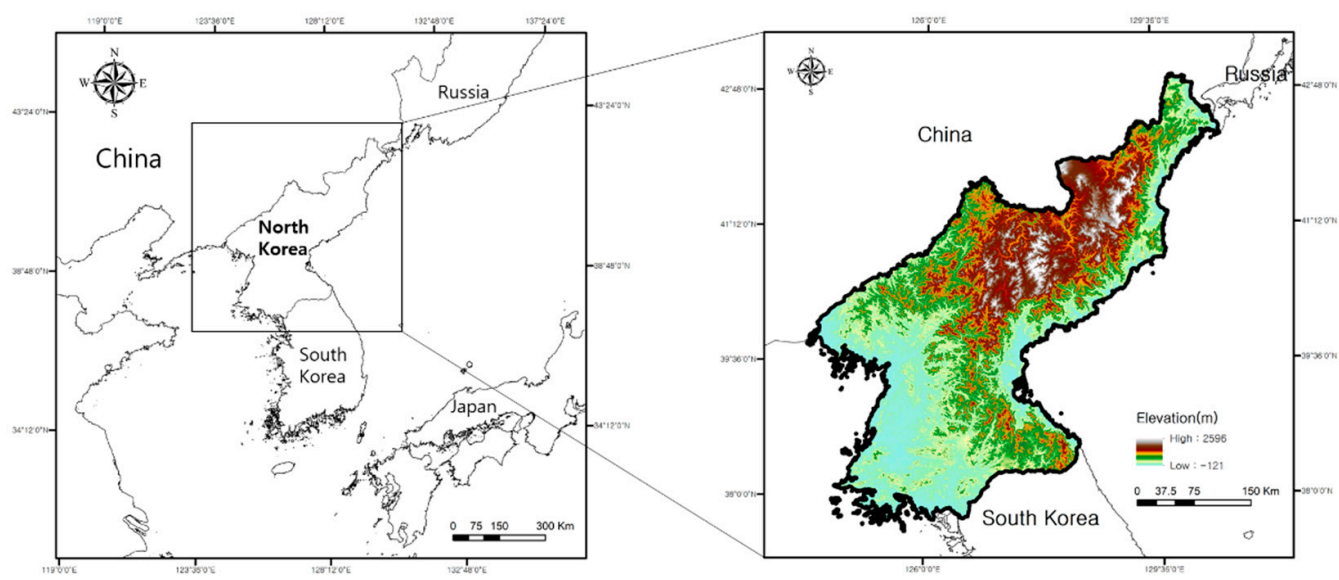

Figure 1. Study area: North Korea, Korean Peninsula. (Democratic People's Republic of Korea; DPRK).

\section{Materials and Methods}

\subsection{Study Overview}

The research flowchart (Figure 2) outlines the research steps of the LULC classification method and change detection. First, Landsat top-of-atmosphere (TOA) reflectance products are used for land classification based on cloud mosaic, and multi-year image synthesis methods were applied. Second, based on the principles of "complete consistency" and "temporal stability" [12]; sample points were filtered from five land cover types: builtup, cropland, forest, grassland, and water bodies. Third, based on the filtered sample points, Random Forest machine learning was used to classify the input bands for LULC classification in North Korea. The accuracy of the classification results was validated using training data. Finally, according to change detection method, which involves pixel-based classification result images, the total area and change of each LULC class was calculated to assess and analyze LULCC patterns.

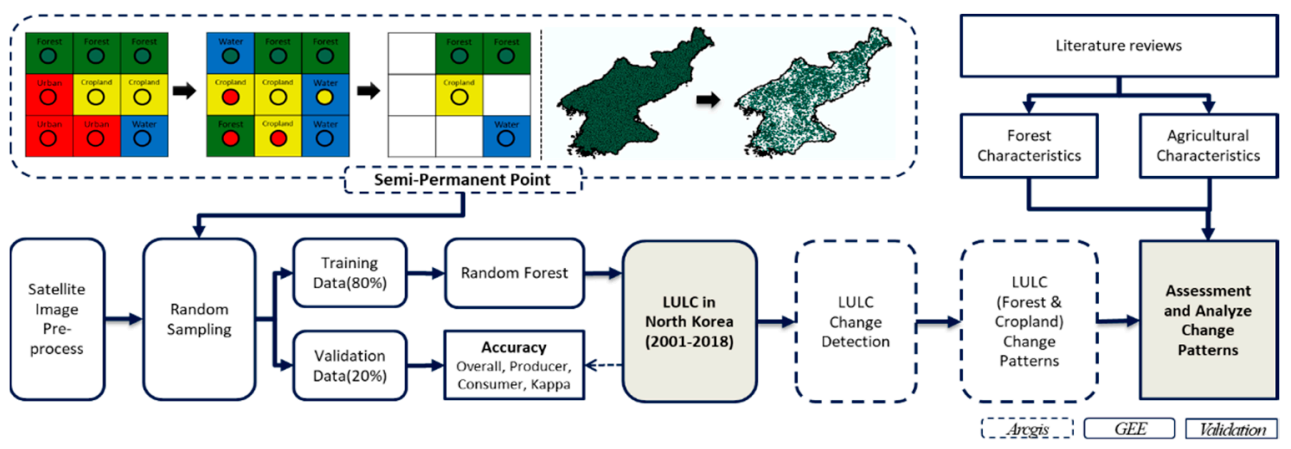

Figure 2. Research flow chart.

\subsection{Data Collection}

The method we applied relies on the use of multi-temporal and multi-spectral images for classifying forest areas by combining the land-cover type characteristics identified in the study area. We obtained the Landsat TOA product dataset and the Shuttle Radar Topography Mission V3 product (SRTM Plus) [33] digital elevation data, Defense Meteorological Program (DMSP), Operational Line-Scan System (OLS) [34], and NPOESS Preparatory Project (NPP) data. We also used visible infrared imaging radiometer suite (VIIRS) [35] data, which provided two different night lighting products (Table 1). 
Table 1. Classification of Data Sources.

\begin{tabular}{|c|c|c|c|c|}
\hline Class & Data & Year & Term & Resolution \\
\hline \multirow{4}{*}{ Satellite Image } & Landsat & 2000-2019 & 16 days & $30 \mathrm{~m}$ \\
\hline & $\begin{array}{c}\text { Defense Meteorological Program } \\
\text { (DMSP)/Operational Line-Scan } \\
\text { System (OLS) }\end{array}$ & 2001-2012 & 1 year & 30 arc seconds \\
\hline & $\begin{array}{l}\text { NPOESS Preparatory Project } \\
\text { (NPP)/Visible Infrared Imaging } \\
\text { Radiometer Suite (VIIRS) }\end{array}$ & 2012-2017 & 1 month & 15 arc seconds \\
\hline & $\begin{array}{c}\text { Shuttle Radar Topography Mission V3 } \\
\text { product (SRTM3) }\end{array}$ & 2000 & - & $30 \mathrm{~m}$ \\
\hline \multirow{5}{*}{$\begin{array}{l}\text { Land use and land } \\
\text { cover (LULC) } \\
\text { Product }\end{array}$} & MCD12Q1.006 & 2001-2018 & 1 year & $500 \mathrm{~m}$ \\
\hline & $\begin{array}{l}\text { Finer Resolution Observation and } \\
\text { Monitoring of Global Land Cover } \\
\text { (FROM-GLC) }\end{array}$ & 2017 & - & $30 \mathrm{~m}$ \\
\hline & Global land cover (GLC30) & 2010 & - & $30 \mathrm{~m}$ \\
\hline & Global Forest Change dataset (GFCD) & 2000 & - & $30 \mathrm{~m}$ \\
\hline & $\begin{array}{l}\text { Global Food Security-support } \\
\text { Analysis Data Extent Southeast and } \\
\text { Northeast Asia (GFSAD30SEACE) }\end{array}$ & 2015 & - & $30 \mathrm{~m}$ \\
\hline
\end{tabular}

All land cover products had a $30 \mathrm{~m}$ resolution, with the exception of the MODIS land cover products. Thus, we used $500 \mathrm{~m}$ low resolution MODIS Land Cover Type Product (MCD12Q1) data in combination with $30 \mathrm{~m}$ high resolution products such as the Global Forest Change dataset (GFCD) [36], global land cover (GLC30) [37], Finer Resolution Observation and Monitoring of Global Land Cover (FROM-GLC) [38,39], and Global Food Security-support Analysis Data Extent Southeast and Northeast Asia (GFSAD30SEACE) [40] (Table 1).

\subsection{Data Collection and Processing}

The current traditional methods to increase the number of training data points mainly include field surveys and artificial visual interpretation, such as using google earth, Quickbird, Bing maps, etc. However, supervised classification usually requires a certain number of training samples and verification samples. As in the study of Jin et al. [6], field surveys and artificial visual interpretation are used in large areas with large landscape heterogeneity; it requires manpower and time, so the cost is extremely high. To overcome these problems and generate a highly reliable reference dataset, we applied authoritative land cover products [12], with some modifications, to construct a training sample database. This method is based on the overlay of the analysis of randomly generated points with existing LULC products and filtered out points with inconsistent classification attributes to obtain sample points under multi-source LULC products [12,13]. Additionally, to balance the sample and avoid an accuracy deviation caused by excessive density, we re-filtered the sample points according to the area ratio of the land cover types. The 2010 LULC data from the Ministry of Environment (MOE) was used to define the area ratio by land cover type. In addition, different products were used in the present methodology based on the methodology principles of "complete consistency" and "temporal stability". All land cover maps except than MODIS LULC products (MCD12Q1) were selected, which is $30 \mathrm{~m}$ resolution products (FROM-GLC, GLC30, GFCD, GFSAD30SEACE). This was improved to reduce uncertainty about point filtering such as homogeneity and geographic integrity [15].

During satellite image pre-processing, we first sorted the image data from April to July of a predetermined year, as well as the year before and after, to identify pixels with cloud coverage below $40 \%$. Using these selected images, we obtained high-quality no- 
cloud satellite image data and reclassified all LULC products (MCD12Q1, FROM-GLC, GLC30, GFCD, GFSAD30SEACE) of the study area into five types: built-up, cropland, forest, grassland, and water bodies. In this study, wetland cover was included in the water body cover based on the research method used and the regional characteristics. These land cover types were used to filter the training and verification sample points. We must note that bare land type was not included in the analysis because that cannot be generated in the sampling process. Reclassifying the MCD12Q1, GFCD, GLC30, FROM-GLC, and GFSAD30SEACE data into LULC types generated overlay products and filter sample points. During sample point processing, based on the overlay the analysis, we randomly generated 10,000 sample points across North Korea, imported the attributes of the above 5 LULC products, and filtered out sample points with different attributes. Among the 10,000 randomly selected sample points, 4853 sample points were filtered for classification.

\subsection{Classification Process}

For successful classification, an efficient classifier must be selected to classify spatial characteristics of spectra and other variables using a small number of training samples [41,42]. Machine learning-based classifiers are particularly useful for identifying patterns in complex functional spatial characteristics while minimizing the problem of data dimensionality [43]. Based on previous studies, RF has shown excellent performance in LULC classification [11,23]. We used the RF [44] machine learning algorithm for the LULC classification for the following reasons: 1 . Variables with different characteristics can be handled together; 2 . Insensitive to noise, outliers, and overtraining; 3. Rapid analysis and efficiency [11,45,46]. In addition, according to a systematic review of GEE from 2010 to 2019, the RF algorithm is one of the most frequently used classification algorithms [25]. Therefore, this study used the RF algorithm with GEE for classification. Random Forest consists of multiple independent and unrelated decision trees. Each decision tree is judged according to the input samples and variables and predicts the category to which the samples should belong to [44]. Among 4853 sample points, 80\% (3882) of the sample points were used for training and 20\% (971) were used for validation. The number of decision trees (ntree) was set to 500, which was found to be sufficient in previous experiments [47]. Furthermore, the NDVI [48], NDWI [49], SRTM products, DMSP/OLS, and NPP/VIIRS products were entered as input data for the Random Forest classification.

The NDVI was determined as follows:

$$
N D V I=\frac{(N I R-R e d)}{(N I R+R e d)}
$$

and the NDWI was determined as follows:

$$
N D W I=\frac{(\text { Green }-N I R)}{(\text { Green }+ \text { NIR })}
$$

where green, red, and NIR are the surface reflectance of the 3,4 and 5 bands of the Landsat OLI products, and the surface reflectance of the 2, 3 and 4 bands of Landsat TM products, respectively.

In this study, most processes were completed on the Google Earth Engine (GEE) platform [28], which is a highly efficient free cloud platform for processing and analyzing satellite image data [50]. 


\subsection{LULCC Analysis}

For change detection using the classification results to observe the trend of forest changes in North Korea, the LULC classification results of this study were analyzed based on the ArcGIS 10.8 platform [51]. From these pixel-based classification result images, the total area and change of each LULC class in the study area were calculated. In the change detection, Formulas (3) and (4) are used to calculate the total area and change of each LULC class in the study area from these pixel-based classification result images, and Formula (5) was used to calculate the rate of change in the study area from 2001 to 2018.

The proportion of each LULC type used was calculated as follows:

$$
A_{i} \%=\frac{A_{i}}{A_{t}} \times 100 \%
$$

The change for each LULC type was calculated as follows:

$$
A_{i}=A_{i} t 1-A_{i} t 2
$$

The annual rate of change for each LULC type was calculated as follows:

$$
A_{i r}=\left(\frac{A_{i} t 1}{A_{i} t 2}-1\right) \times 100 \%
$$

where $A_{i}$ refers to the area of the LULC type $i, A_{t}$ denotes the total study area, and $A_{i} \%$ denotes the proportion of each LULC type area. $A_{i} t 1$ and $A_{i} t 2$ refer to the total area of LULC type $i$ in specific years 1 and 2, respectively [52]. $A_{\text {ir }}$ refers to the rate of change, which is the magnitude of change between the specified years, and the range of change from 2001 to 2018 was analyzed in this study [53]

\subsection{Classification Accuracy Validation}

To verify the time-series classification results, a confusion matrix including the overall accuracy (OA), user's accuracy (UA), producer's accuracy (PA), and kappa coefficient [54] was used. Additionally, to overcome the uncertainties of the LULC classification results, we additionally cross-validated Random Forest, and then generated the final LULC classification results based on the average classification results of all validation. The plus-minus sign $( \pm)$ is used to illustrate the annual accuracy change range from 2001 to 2018 . We evaluated the accuracy of classification for a total of five classification types in the level 1 classification system, except for bare land, which could not be classified in this study. Due to the characteristics of the study area and used methodology, the bare land was eliminated during the sampling process. The five classification types were built-up, cropland, forest, grassland, and water bodies; wetlands were included in the water bodies category in this study. In addition, visual interpretation was conducted through comparison with other existing LULC classification products, MOD12Q1, FROMGLC2017, and high-resolution satellite images obtained via Google Earth [12]. Because of global LULC, products such as FROMGLC still require further verification at the international level to determine whether they are useful in other applications [55].

\section{Results}

\subsection{LULC Classification Accuracy Assessment}

The classification results in Table 2 show that the classification accuracy of cropland, forest, and water bodies was higher than that of the other land cover types in North Korea from 2001 to 2018. The overall accuracy and kappa coefficient were $98.2 \% \pm 1.6 \%$ and $0.959 \pm 0.037$, respectively. The accuracy satisfies the standard proposed by researchers in other studies $[6,56,57]$. The results of the classes are presented in Table 2. The forest and cropland producer's and user's accuracies were extremely high. The forest user's and producer's accuracies were $98.9 \% \pm 1.1 \%$ and $99.7 \% \pm 0.3 \%$, respectively. The cropland 
user's and producer's accuracies were $95.5 \% \pm 4.5 \%$ and $97.8 \% \pm 2.2 \%$, respectively. The built-up area type also had high accuracy, where the user's and producer's accuracies were $91.7 \% \pm 8.3 \%$ and $85.3 \% \pm 14.7 \%$, respectively. Meanwhile, the classification accuracy of the grassland was low, with user and producer accuracies of $72.9 \% \pm 27.1 \%$ and $66.7 \% \pm 33.3 \%$, respectively. Because land cover classification uses sample points that are filtered from a land area that has remained unchanged for many years, the accuracies of the stable classes such as croplands, forests, and water bodies are extremely high after verification [12].

Table 2. Land cover classification accuracy from 2001 to 2018.

\begin{tabular}{ccc}
\hline Land Cover & User's Accuracy & Producer's Accuracy \\
\hline Built-up & $91.7 \% \pm 8.3 \%$ & $85.3 \% \pm 14.7 \%$ \\
Cropland & $95.5 \% \pm 4.5 \%$ & $97.8 \% \pm 2.2 \%$ \\
Forest & $98.9 \% \pm 1.1 \%$ & $99.7 \% \pm 0.3 \%$ \\
Grassland & $72.9 \% \pm 27.1 \%$ & $66.7 \% \pm 33.3 \%$ \\
Water bodies & $96.7 \% \pm 3.3 \%$ & $95 \% \pm 5 \%$ \\
Overall Accuracy & & Kappa Coefficient \\
\cline { 2 - 3 } & $98.2 \% \pm 1.6 \%$ & $0.959 \pm 0.037$ \\
\hline
\end{tabular}

Our classification results were then visually compared with the MOD12Q1 and FROMGLC land cover classification products, as well as high-resolution images obtained via Google Earth. As shown in Figure 3, compared with Google Earth's high-resolution satellite images, the classification result largely reflects the real land type. Furthermore, the quality of our land cover classification is better than that of the MOD12Q1 product and somewhat similar to that of the FROMGLC product. However, it is worth to note that our results are better than the FROMGLC products with regard to classification aggregation.

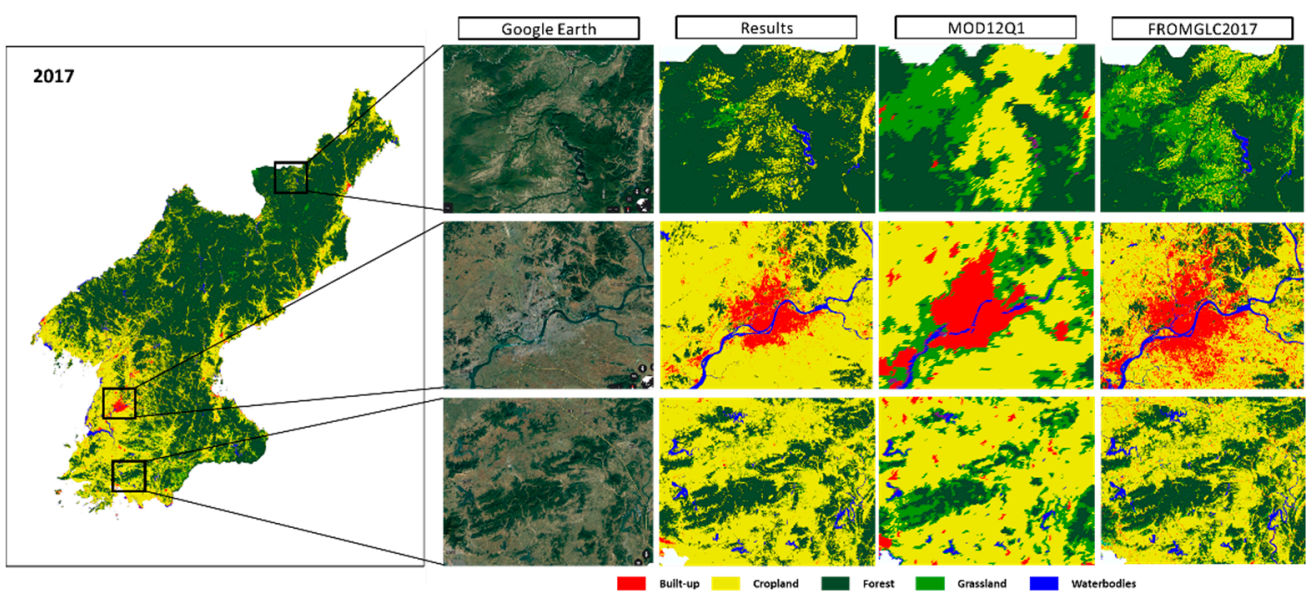

Figure 3. Image validation and comparison of different land cover products in 2017.

\subsection{LULC Classification Results}

The $30 \mathrm{~m}$ resolution land cover map was classified using sample points and the Random Forest algorithm with in long term timeseries in 2001-2018, sorting the data into built-up, cropland, forest, grassland, and water bodies (wetland), as shown in Figure 4. Note that bare land is not reflected in the classification results of the study area. The reason is that the bare land and grassland in the study area are similar in spectrum and the bare land area is extremely small, so the bare land in the LULC product used in this study is so different that the sampling method applied cannot filter out the bare land sample. 
Figure 5 shows that the main land types of LULC in North Korea are forest and cropland. The largest change in the 18-year study period was the restoration of the forest cover type in the south and central mountains. Further, the concentrated expansion of croplands in the north and west regions were also large changes.

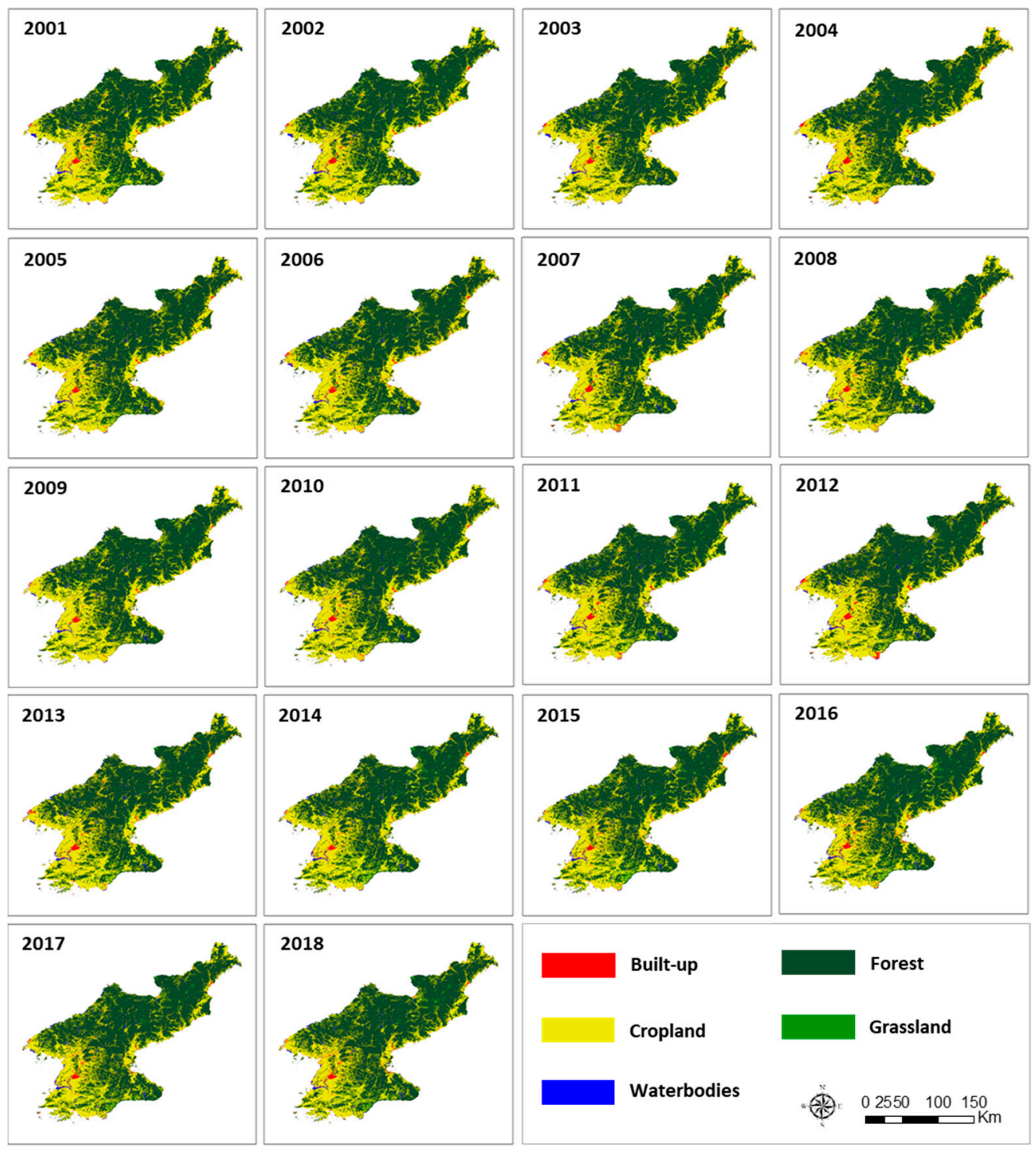

Figure 4. Land use and land cover classification maps for 2001 to 2018.

\subsection{LULC Change Detection}

The Table 3 shows the area percentage and change rate of 5 LULC types: built-up, cropland, forest, grassland, and waterbodies. Observing the changes in the entire study area showed that croplands and forests were the main types of changes, while the changes in built-up areas and waterbodies were not obvious. However, since most of the land cover areas in North Korea were croplands and forests, according to the proportion of the entire study area, built-up areas had a clear expansion trend. Relatively, the built-up area increased significantly from 2001 to 2018, with a change rate of $37.26 \%$. In addition, the forest and water body areas increased at rates of $2.59 \%$ and $4.73 \%$, respectively. Conversely, the cropland and grassland areas showed decreasing trends at change rates of $-5.17 \%$ and $-7.11 \%$, respectively. 


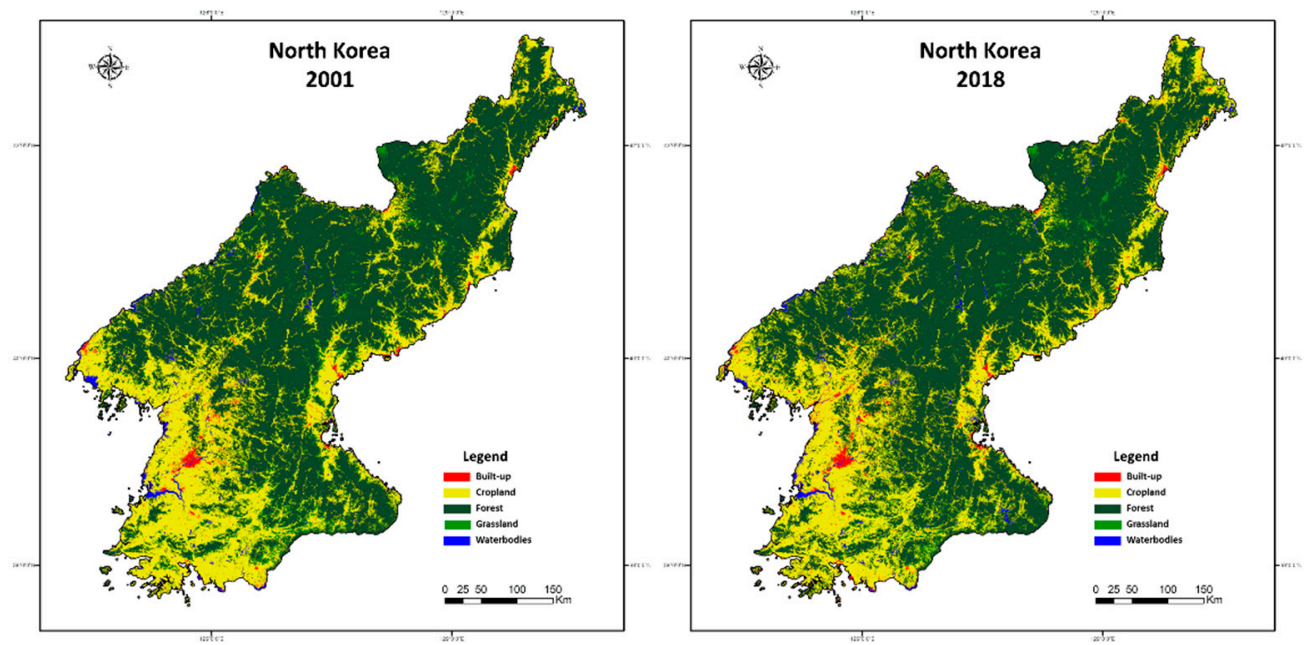

Figure 5. Land use and land cover classification maps for 2001 and 2018.

Table 3. Land use and land cover area percentage and change rate for 2001 and 2018.

\begin{tabular}{cccc}
\hline Class & Area 2001 & Area 2018 & Change Rate \\
\hline Built-up & $0.789 \%$ & $1.083 \%$ & $37.26 \%$ \\
Cropland & $30.832 \%$ & $29.237 \%$ & $-5.17 \%$ \\
Forest & $61.917 \%$ & $63.520 \%$ & $2.59 \%$ \\
Grassland & $5.126 \%$ & $4.761 \%$ & $-7.11 \%$ \\
Water bodies & $1.336 \%$ & $1.399 \%$ & $4.73 \%$ \\
\hline Total & $100.00 \%$ & $100.00 \%$ & \\
\hline
\end{tabular}

North Korea's built-up cover area growth $(0.789 \%$ to $1.083 \%)$ and change rate $(37.26 \%)$ are consistent with the country's existing urbanization rate information [58]. That is, from $59.491 \%$ in 2001 to $61.899 \%$ in 2018, the urbanization rate of North Korea increased by about $2.408 \%$ [58]. The reduction in the area covered by croplands ( $30.832 \%$ to $29.237 \%)$ was the same as the country's current Agricultural Productivity Indicators change trend, from 2.50 in 2001 to 2.43 in 2018. According to North Korea's forest survey report, the annual change rate of the country's forest coverage from 2008 to 2018 grew by $1.10 \%$ [59]. This was similar to the area growth $(61.917 \%$ to $63.520 \%)$ and change trend $(2.59 \%)$ of the forest cover in this study. Additionally, the growth of water bodies (1.336\% to $1.399 \%$ ) can be attributed to the emergence of new water bodies between 2001 and 2018.

The Table 4 shows the forest and cropland transfer between 2001 and 2018. Table 4 revealed that the expansion of croplands was at the cost of forests. On the contrary, the restoration of forests was mainly at the cost of the return of croplands.

Table 4. Forest and cropland transfer between 2001-2018 per 3 years in North Korea. The numbers indicate the percentage of the area of the land cover type based on the total study area. C: Cropland; F: Forest; G: Grassland.

\begin{tabular}{ccccccc}
\hline Class & $\mathbf{2 0 0 1 - 2 0 0 4}$ & $\mathbf{2 0 0 4 - 2 0 0 7}$ & $\mathbf{2 0 0 7 - 2 0 1 0}$ & $\mathbf{2 0 1 0 - 2 0 1 3}$ & $\mathbf{2 0 1 3 - 2 0 1 6}$ & $\mathbf{2 0 1 6 - 2 0 1 8}$ \\
\hline C to C & $27.08 \%$ & $27.44 \%$ & $27.16 \%$ & $26.73 \%$ & $26.51 \%$ & $26.49 \%$ \\
C to F & $2.40 \%$ & $2.46 \%$ & $2.64 \%$ & $1.86 \%$ & $1.77 \%$ & $0.73 \%$ \\
C to G & $0.62 \%$ & $1.28 \%$ & $0.95 \%$ & $1.66 \%$ & $2.35 \%$ & $0.94 \%$ \\
F to C & $2.32 \%$ & $2.51 \%$ & $2.14 \%$ & $2.94 \%$ & $0.78 \%$ & $0.65 \%$ \\
F to F & $58.73 \%$ & $59.42 \%$ & $59.59 \%$ & $59.04 \%$ & $59.33 \%$ & $60.84 \%$ \\
F to G & $0.82 \%$ & $1.25 \%$ & $1.12 \%$ & $1.52 \%$ & $1.89 \%$ & $0.94 \%$ \\
\hline
\end{tabular}

Croplands underwent significant changes from 2013 to 2016, which can be attributed to the 2015 extreme drought in North Korea [60]. According to statistics on agricultural 
production in North Korea [58,61], the total crop output in 2015 was significantly lower than that of other years, which indirectly led to the transfer of a part of croplands to grass-lands.

Interestingly, from 2001 to 2013, the mutual transfer trend between forests and croplands was obvious. This can be attributed to the improvement of North Korea's forest laws and the implementation of the "10-year plan for forest restoration" [62,63] (more de-tails in Section 5.1). Additionally, after 2013, croplands mainly transferred into forests, and forests no longer showed obvious signs of transferring into croplands. This is also one of the turning points for the success of the North Korean afforestation business which was reported by the country in 2013 [59].

Figure 6 illustrates the spatial distribution of LULCC from 2001 to 2018, wherein significant changes occurred primarily in built-up, cropland, and forest areas. The cropland area experienced a loss caused by both the expansion of major cities and cropland changing into forest land. This is due to the formulation and improvement of North Korea's forest policies, which began in the 1990s [62]. Since 2000, a series of amendments and additions such as the "10-year plan for forest restoration" [63] resulted in the restoration of croplands into forests [64]. Overall, North Korea has seen significant changes in forest and cropland land cover from 2001 to 2018, although the total area has not changed to a large extent. This lack of total area change is because, although most of the cropland in the southern and central mountainous areas have been converted to forest, the croplands in the western and northern regions have begun to expand, leading to forest loss.

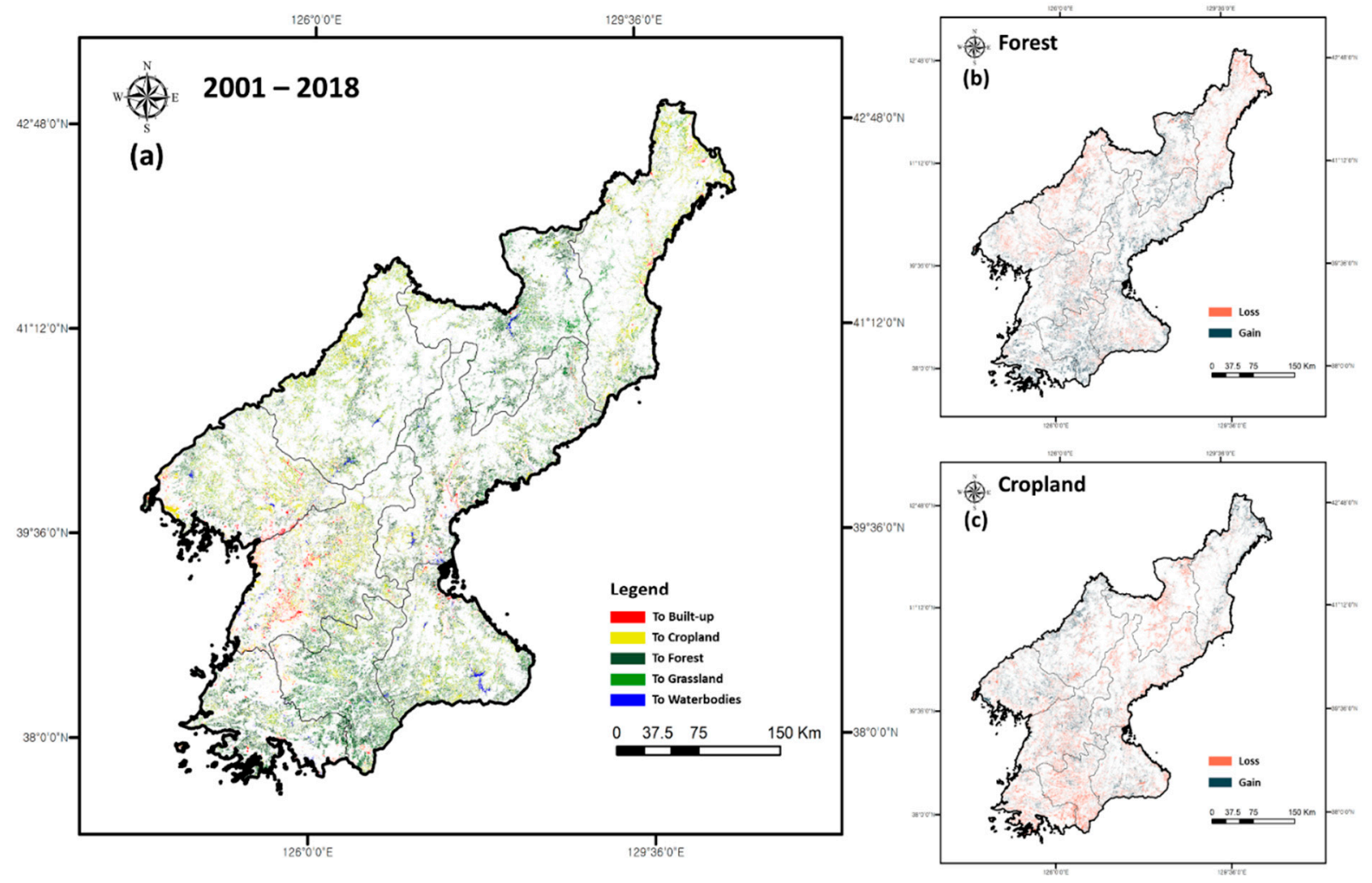

Figure 6. (a) Land use and land cover change map for 2001 and 2018, and (b) forest land loss and gain, and (c) cropland land loss and gain. 


\subsection{Relation with Terrace Field and Elevation}

Figure 7 shows the relation between forest and cropland areas with elevation from 2001 to 2018. Here, it is clear that below $900 \mathrm{~m}$, the overall area change is uniform, while there is a clear decrease in cropland below $300 \mathrm{~m}$. This decrease occurred because around the time of this study period, new watersheds gradually began to appear. Therefore, the land that was originally cropland in 2001 was replaced by new watersheds in low-elevation areas in 2018. Above $900 \mathrm{~m}$, there was an increase in forest area and a decrease in cropland, indicating a decrease in croplands in the mountainous areas of North Korea concomitant with forest restoration. In other words, the terrace field gradually decreased over time as forest restoration continued. In general, at an elevation greater than or equal to $900 \mathrm{~m}$, terrace fields were reduced, and forest restoration increased. Meanwhile, the overall change in cropland at less than $900 \mathrm{~m}$ was balanced.

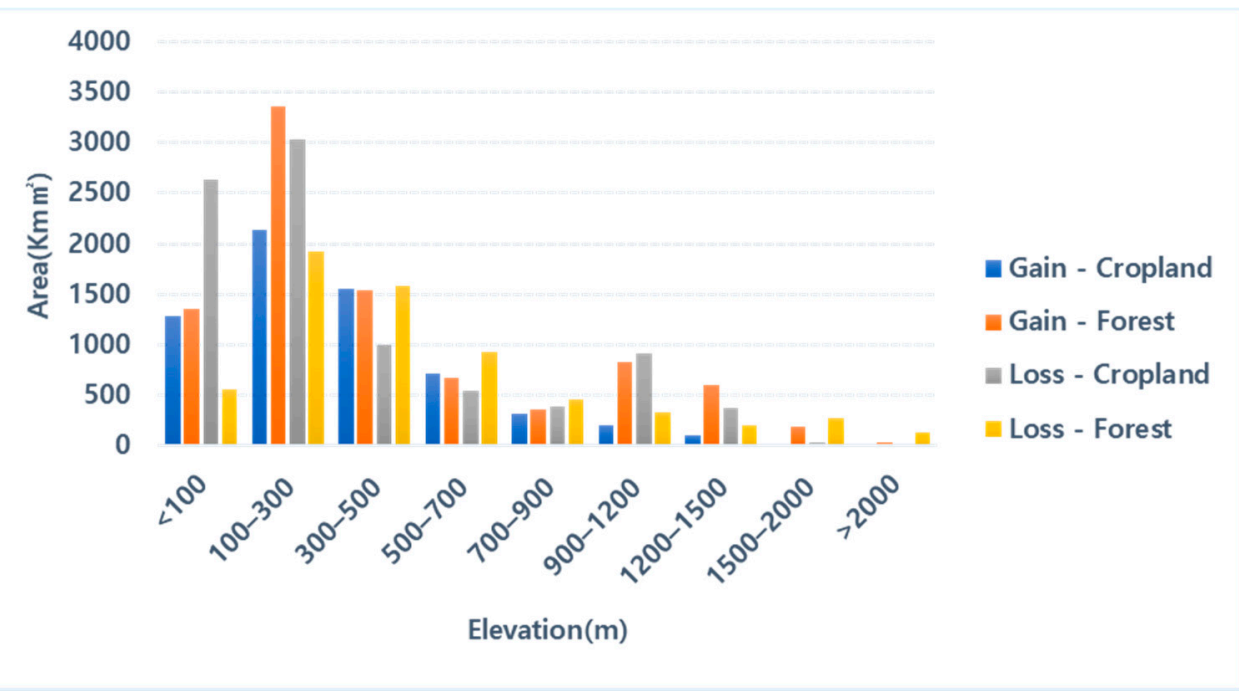

Figure 7. Forest and cropland area loss and gain related to elevation.

\section{Discussion}

\subsection{Interpretation and Explanation of the Forest Change in North Korea}

North Korea is a developing country, with primary industries, including mining, light industry, and agriculture, accounting for its main economic income. According to statistics from 1990 to 2014, agriculture, forestry, and fisheries comprised the second-highest economic income ranking after the service industry. Further, based on estimates from the Bank of Korea, the industrial structure of North Korea, based on the nominal GDP in 2014, comprises $21.8 \%$ agriculture, forestry, and fishing; $13.1 \%$ mining; $21.3 \%$ manufacturing; $31.3 \%$ service; and $8.2 \%$ construction [65]. This could explain the high contribution of agriculture to North Korea's major economic resources. Since the mid-1970s, North Korea has expanded its terrace fields. On 11 December 1992, North Korea officially enacted the "Forest Law," the first dedicated North Korean forest law [62]. North Korea's continuous expansion of terrace field is somewhat unavoidable, as more than $80 \%$ of its land area is mountainous and agriculture is one of its major economic industries. Nevertheless, in June 2000 and October 2001, the Forest Law was strengthened through amendments and supplements [62]. These amendments were included owing to continued food and energy shortages, as well as the expansion of terrace field and deforestation. The resultant increases in forest areas and human activity have led to a rapidly increasing number of wildfires. In fact, many studies on North Korea have revealed various fundamental problems, including a lack of disaster response capabilities [66], energy shortages [62], a decline in agricultural production [9,67], and water resource depletion [68,69], which seems to have had an indirect effect on the strengthening of the Forest Law. Later, on 
2 August 2005, in a supplement to a Forest Law amendment, afforestation, reforestation, and restrained logging were emphasized.

Therefore, the development of agriculture, one of North Korea's main economic industries, does not comply with the imposed forest law, which was formulated to reduce deforestation caused by excessive terrace field expansion and deforestation. Therefore, as North Korea enters the modern era, it must conduct reforestation while simultaneously maintaining agriculture as an important economy [70]. Thus, constructing geospatial information for North Korea and analyzing its land cover changes is of utmost importance. Through the spatial and geographic analysis of major land cover changes, this study addresses both the restoration of the southern and central agricultural areas to forest areas and the expansion of western and northern forest areas to agricultural areas.

\subsection{Importance of Spatial Analysis and Future Research Directions}

Figures 6 and 7 as well as Table 3 illustrate the differences between the overall numerical LULC change trend and the spatial LULC change trend across North Korea. In the detailed spatial analysis, the specific areas and ranges of specific growth or reduction of each LULC type can be determined at the spatial level, and further relevant analyses can be performed according to the characteristics of the change area, such as the driving mechanism [12,53], or according to the national or regional policy of the change trend [53,71]. As shown in Figure 7, the change trend can be analyzed on a multi-dimensional level via the spatial analysis, such as via elevation or slope-related analysis, to discover more LULCC information $[7,72]$. The changes in North Korea's forests and cropland illustrate this aspect. The area changes in North Korea's forests from 2001 to 2018 as shown in Table 3 are extremely small, ranging from $61.917 \%$ in 2001 to $63.520 \%$ in 2018 , and increasing only by $1.603 \%$. However, from the spatial change trends shown in Figure 6, although the overall area of North Korea's forests changes only slightly, the increase in forest cover in southern and central Korea is extremely clear on a spatial level. The area of cropland in North Korea has also not changed significantly. Table 3 shows a change from $30.832 \%$ in 2001 to $29.237 \%$ in 2018, implying a decrease by only $1.595 \%$. However, Figure 6 shows that the southern and central regions have decreased significantly in area, and the area of North Korea has increased significantly in the western and northern regions. This shows that in a large-scale LULCC analysis, relying solely on the overall judgment of the data change trend does not yield entirely accurate results. Rather, combining the multi-dimensional space can yield a more accurate judgement of the growth or decrease trend of the LULC. Most of the changes in North Korea's LULC are related to human interference and the impact of national and regional policies [73,74]. In this regard, more research on spatial change analysis is required in the future. For example, future research can focus on the analysis of the geographical characteristics or related changes in policies according to the division in administrative regions or the location or the watershed [71,75], and an analysis of the main driving mechanism of the LULC changes according to spatial geographic data, such as the combination of biophysical data (climate, geology) and human factors (society, economy, politics, culture, and population) [76].

\subsection{Advantage of Time Series Image Composite on Google Earth Engine}

In this study, we selected time series data from June to August (the season with maximum potential vegetation activity) [26]. Next, we composited the data of the same period, 3 years before and after the stud period, to fill in blank parts of the cloudy summer images to reduce the impact of cloud interference on classification accuracy [31]. The image composite was generated using temporal aggregation methods most used in GEE.

Most of the traditional image composites tended to include images from the dataset with no cloud or less cloud coverage (\%) to construct the LULC map [14]. However, this method has limitations in large-scale LULC mapping, such as the inability to completely solve the cloud coverage problem. Further, this method involved processing large amounts of data and the load on a personal computer is extremely large. The emergence of the 
GEE cloud platform solves the problems. The computing power based on the GEE cloud platform and the data catalog that can access multiple satellite data and products make it easy for researchers to access and greatly reduce the manpower, cost, and time required. At the same time, previous studies have shown that temporal aggregation is a promising tool [29], which when combined with GEE, can effectively composite large amounts of data to produce cloudless high-quality images for LULC classification and maintain high accuracy of classification $[12,14,29]$. This makes it possible to use its huge image catalog to build long-term sequence data and analyze the long-term trends (such as LULCC) that it produces. The classification results in this study also prove the reliability of the GEE cloud platform as a remote sensing analysis tool [28].

The emergence of the GEE cloud platform has greatly accelerated the processing and analysis of remote sensing data. This will make it easier for more researchers to keep abreast of developments in the remote sensing field, because it is not restricted by personal equipment, time, and funds [28]. In addition, the integrated algorithm and code form (JavaScript, Python) on GEE combined with data upload service will make it possible to make rapid spatial predictions on GEE, such as disaster sensitivity analysis and species potential habitat prediction.

\subsection{Classification Limits and Advantages in North Korea}

The sampling method used in this study uses the same pixel values for various data [12]. This may result in land cover classification not being possible in some situations if the land cover class of the study site is diverse and complex or the class area occupied is small. Thus, for North Korea, we incorporated wetland areas in the waterbody land cover type, as wetlands occupy only a small area and cannot be classified. Regarding the overall LULC classification accuracy, as it is difficult to distinguish bare land, grassland, and shrub, which all have similar spectra, the overall accuracy for grassland is much lower than that for the other land cover types [12]. In addition, the timing of satellite image data capture and the amount of data accumulation significantly affect the efficacy of the sampling method. Therefore, data analysis is only available within a limited time series; thus, for LULC classification, only major land cover types can be classified. However, this method is extremely useful for observing time-series changes, constructing data for inaccessible areas, and producing highly accurate and reliable results for the major types of land cover. Thus, we can not only obtain high-accuracy time-series LULC maps for inaccessible areas, but also analyze the characteristics of land cover change in the study region.

\section{Conclusions}

An LULC map of North Korea for the period 2001-2018 was constructed using Random Forest algorithm based on Landsat multi-temporal image and NDVI and NDWIacquired Google Engine. Through the change detection technique, the overall change in North Korean land cover between 2001 and 2018 and its forest changes were evaluated. Following a classification of land cover of the study area into five categories, built-up, cropland, forest, grassland, and waterbodies (wetland included), our classification overall accuracy was $98.2 \% \pm 1.6 \%$, and the Kappa coefficient was $0.959 \pm 0.037$. Moreover, our research improved cropland classification accuracy and forest classification accuracy. It has high-reliability and important significance for analyzing the changing trend of forests. From 2001 to 2018, the rates of change in the built-up, agricultural, forest, grassland, and waterbody areas were $37.26 \%, 5.17 \%, 2.59 \%, 7.11 \%$, and $4.73 \%$, respectively. In general, observing the changes in the entire study area showed that croplands and forests were the main types of changes, while the changes in built-up areas and waterbodies were not obvious, but built-up areas had a clear expansion trend. In addition, distinct spatial changes were observed. The most evident spatial change was the restoration of forests in the southern and central regions and the increase in cropland in the north and west. 
By examining the current literature related to North Korea's forests and croplands, we constructed an elevation relation to make further inferences based on the analysis of land cover change. Based on this, we propose that one of North Korea's main economic industries is agriculture, which conflicts with the forest protection laws currently in place. To maintain its agricultural industry, North Korea has expanded terrace field in its mountainous terrain. However, with the strengthening of forest protection policies, this terrace field is now the target of reforestation. Furthermore, a related analysis between changing cropland and forest areas with elevation revealed that cropland cover is decreasing while forest cover is increasing at elevations above $900 \mathrm{~m}$.

As a matter of fact, this study does not only present improved cropland and forest classification accuracy, with an emphasis on monitoring the trend of forest restoration in North Korea, which is an inaccessible area. In other words, we used the LULC map with high forest and cropland coverage accuracy, focusing on the use of change detection and spatial analysis to analyze the restoration trend of North Korea's forests. Our research shows that the forests in the southern and central regions of North Korea are undergoing restoration. This result could provide an important reference for the regional environmental management and ecological security in North Korea. On the other hand, the results also raise new problems regarding the main factors affecting the changes in LULC in North Korea and to what extent these factors can be constructed in North Korea, which is an inaccessible area.

Author Contributions: All authors made substantial contributions to conception and design of the study. Y.P. performed the experiments, analyzed the data, and wrote the paper. S.P. discussed the results and edited the manuscript. S.J. and D.L. guided the research and reviewed the manuscript. All authors have read and agreed to the published version of the manuscript.

Funding: This work was supported by a grant from the National Institute of Biological Resources (NIBR), funded by the Ministry of Environment (MOE) of the Republic of Korea (NIBR202108101).

Institutional Review Board Statement: Not applicable.

Informed Consent Statement: Not applicable.

Data Availability Statement: The data that support the findings of this study are available on request from the corresponding author.

Acknowledgments: Thanks to all anonymous reviewers and editors for taking the time to review this paper. The suggestions and comments of anonymous reviewers and editors have greatly improved the overall quality of the paper. This is a valuable experience in my research career, thanks again.

Conflicts of Interest: The authors declare no conflict of interest.

\section{References}

1. McKinley, D.C.; Ryan, M.; Birdsey, R.A.; Giardina, C.P.; Harmon, M.E.; Heath, L.S.; Houghton, R.A.; Jackson, R.B.; Morrison, J.F.; Murray, B.C.; et al. A synthesis of current knowledge on forests and carbon storage in the United States. Ecol. Appl. 2011, 21, 1902-1924. [CrossRef] [PubMed]

2. Hosonuma, N.; Herold, M.; De Sy, V.; De Fries, R.S.; Brockhaus, M.; Verchot, L.; Angelsen, A.; Romijn, E. An assessment of deforestation and forest degradation drivers in developing countries. Environ. Res. Lett. 2012, 7, 044009. [CrossRef]

3. Guadalupe, V.; Sotta, E.D.; Santos, V.F.; Aguiar, L.J.G.; Vieira, M.; de Oliveira, C.P.; Siqueira, J.V.N. REDD+ implementation in a high forest low deforestation area: Constraints on monitoring forest carbon emissions. Land Use Policy 2018, 76, 414-421. [CrossRef]

4. Murad, C.A.; Pearse, J. Landsat study of deforestation in the Amazon region of Colombia: Departments of Caquetá and Putumayo. Remote Sens. Appl. Soc. Environ. 2018, 11, 161-171. [CrossRef]

5. Jeong, S.G.; Park, J.; Park, C.H.; Lee, D.K. Terrace fields classification in North Korea using modis multi-temporal image data. J. Korea Soc. Environ. Restor. Technol. 2016, 19, 73-83. [CrossRef]

6. Jin, Y.; Sung, S.; Lee, D.K.; Biging, G.S.; Jeong, S. Mapping deforestation in North Korea using phenology-based multi-index and random forest. Remote Sens. 2016, 8, 997. [CrossRef]

7. Choi, W.; Kang, S.; Choi, J.; Larsen, J.J.; Oh, C.; Na, Y.-G. Characteristics of deforestation in the Democratic People's Republic of Korea (North Korea) between the 1980s and 2000s. Reg. Environ. Chang. 2016, 17, 379-388. [CrossRef]

8. Kang, S.; Choi, W. Forest cover changes in North Korea since the 1980s. Reg. Environ. Chang. 2014, 14, 347-354. [CrossRef] 
9. Lim, C.-H.; Choi, Y.; Kim, M.; Jeon, S.W.; Lee, W.-K. Impact of deforestation on agro-environmental variables in Cropland, North Korea. Sustainability 2017, 9, 1354. [CrossRef]

10. De Sousa, C.; Fatoyinbo, L.; Neigh, C.; Boucka, F.; Angoue, V.; Larsen, T. Cloud-computing and machine learning in support of country-level land cover and ecosystem extent mapping in Liberia and Gabon. PLoS ONE 2020, 15, e0227438. [CrossRef]

11. Rodriguez-Galiano, V.F.; Ghimire, B.; Rogan, J.; Chica-Olmo, M.; Rigol-Sanchez, J.P. An assessment of the effectiveness of a random forest classifier for land-cover classification. ISPRS J. Photogramm. Remote Sens. 2012, 67, 93-104. [CrossRef]

12. $\mathrm{Hu}, \mathrm{Y}$.; Hu, Y. Land cover changes and their driving mechanisms in Central Asia from 2001 to 2017 supported by google earth engine. Remote Sens. 2019, 11, 554. [CrossRef]

13. Qu, L.; Chen, Z.; Li, M.; Zhi, J.; Wang, H. Accuracy improvements to pixel-based and object-based lulc classification with auxiliary datasets from Google Earth Engine. Remote Sens. 2021, 13, 453. [CrossRef]

14. Inglada, J.; Vincent, A.; Arias, M.; Tardy, B.; Morin, D.; Rodes, I. Operational high resolution land cover map production at the country scale using satellite image time series. Remote Sens. 2017, 9, 95. [CrossRef]

15. Adam, J.O.; Prasad, S.T.; Pardhasaradhi, T.; Xiong, J.; Murali, K.G.; Russell, G.C.; Kamini, Y. Mapping cropland extent of Southeast and Northeast Asia using multi-year time-series landsat 30-m data using a random forest classifier on the Google Earth Engine Cloud. Int. J. Appl. Earth Obs. Geoinf. 2019, 81, 110-124, ISSN 0303-2434. [CrossRef]

16. Bagan, H.; Millington, A.; Takeuchi, W.; Yamagata, Y. Spatiotemporal analysis of deforestation in the Chapare region of Bolivia using landsat images. Land Degrad. Dev. 2020, 31, 3024-3039. [CrossRef]

17. Margono, B.A.; Turubanova, S.; Zhuravleva, I.; Potapov, P.; Tyukavina, A.; Baccini, A.; Goetz, S.; Hansen, M.C. Mapping and monitoring deforestation and forest degradation in Sumatra (Indonesia) using Landsat time series data sets from 1990 to 2010. Environ. Res. Lett. 2012, 7, 034010. [CrossRef]

18. Souza, C.M., Jr.; Siqueira, J.V.; Sales, M.H.; Fonseca, A.V.; Ribeiro, J.G.; Numata, I.; Cochrane, M.; Barber, C.; Roberts, D.; Barlow, J. Ten-year Landsat classification of deforestation and forest degradation in the Brazilian Amazon. Remote Sens. 2013, 5, 5493-5513. [CrossRef]

19. Hütt, C.; Koppe, W.; Miao, Y.; Bareth, G. Best accuracy land use/land cover (lulc) classification to derive crop types using multitemporal, multisensor, and multi-polarization sar satellite images. Remote Sens. 2016, 8, 684. [CrossRef]

20. Ma, J.; Ding, Y.; Cheng, J.C.; Jiang, F.; Tan, Y.; Gan, V.J.; Wan, Z. Identification of high impact factors of air quality on a national scale using big data and machine learning techniques. J. Clean. Prod. 2020, 244, 118955. [CrossRef]

21. Inglada, J.; Arias, M.; Tardy, B.; Hagolle, O.; Valero, S.; Morin, D.; Dedieu, G.; Sepulcre, G.; Bontemps, S.; Defourny, P.; et al. Assessment of an operational system for crop type map production using high temporal and spatial resolution satellite optical imagery. Remote Sens. 2015, 7, 12356-12379. [CrossRef]

22. Müller, H.; Rufin, P.; Griffiths, P.; Siqueira, A.; Hostert, P. Mining dense landsat time series for separating cropland and pasture in a heterogeneous Brazilian savanna landscape. Remote Sens. Environ. 2015, 156, 490-499. [CrossRef]

23. Talukdar, S.; Singha, P.; Mahato, S.; Shahfahad; Pal, S.; Liou, Y.-A.; Rahman, A. Land-use land-cover classification by machine learning classifiers for satellite observations-A review. Remote Sens. 2020, 12, 1135. [CrossRef]

24. Gudex-Cross, D.; Pontius, J.; Adams, A. Enhanced forest cover mapping using spectral unmixing and object-based classification of multi-temporal landsat imagery. Remote Sens. Environ. 2017, 196, 193-204. [CrossRef]

25. Tamiminia, H.; Salehi, B.; Mahdianpari, M.; Quackenbush, L.; Adeli, S.; Brisco, B. Google Earth Engine for geo-big data applications: A meta-analysis and systematic review. ISPRS J. Photogramm. Remote Sens. 2020, 164, 152-170. [CrossRef]

26. Phan, T.N.; Kuch, V.; Lehnert, L. Land cover classification using Google Earth Engine and random forest classifier-The role of image composition. Remote Sens. 2020, 12, 2411. [CrossRef]

27. Dong, J.; Xiao, X. Evolution of regional to global paddy rice mapping methods: A review. ISPRS J. Photogramm. Remote Sens. 2016, 119, 214-227. [CrossRef]

28. Gorelick, N.; Hancher, M.; Dixon, M.; Ilyushchenko, S.; Thau, D.; Moore, R. Google Earth engine: Planetary-scale geospatial analysis for everyone. Remote Sens. Environ. 2017, 202, 18-27. [CrossRef]

29. Carrasco, L.; O'Neil, A.W.; Morton, R.D.; Rowland, C.S. Evaluating combinations of temporally aggregated sentinel-1, sentinel-2 and landsat 8 for land cover mapping with Google Earth Engine. Remote Sens. 2019, 11, 288. [CrossRef]

30. Praticò, S.; Solano, F.; Di Fazio, S.; Modica, G. Machine learning classification of mediterranean forest habitats in Google Earth Engine based on seasonal sentinel-2 time-series and input image composition optimisation. Remote Sens. 2021, 13, 586. [CrossRef]

31. Richards, D.R.; Belcher, R.N. Global changes in urban vegetation cover. Remote Sens. 2020, 12, 23. [CrossRef]

32. Kang, B.-S. Hydrometeorological climate change trend. Meteor. Technol. Pol. Meteor. Admin. 2009, 2, 61-63. (In Korean)

33. Farr, T.G.; Rosen, P.A.; Caro, E.; Crippen, R.; Duren, R.; Hensley, S.; Kobrick, M.; Paller, M.; Rodriguez, E.; Roth, L.; et al. The shuttle radar topography mission. Rev. Geophys. 2007, 45, 583-585. [CrossRef]

34. Elvidge, C.D.; Baugh, K.E.; Kihn, E.A.; Kroehl, H.W.; Davis, E.R. Mapping city lights with nighttime data from the DMSP operational linescan system. Photogramm. Eng. Remote Sens. 1997, 63, 727-734.

35. Miller, S.D.; Straka, W.; Mills, S.P.; Elvidge, C.D.; Lee, T.F.; Solbrig, J.; Walther, A.; Heidinger, A.K.; Weiss, S.C. Illuminating the capabilities of the suomi national polar-orbiting partnership (NPP) visible infrared imaging radiometer suite (VIIRS) day/night band. Remote Sens. 2013, 5, 6717-6766. [CrossRef]

36. Hansen, M.C.; Potapov, P.V.; Moore, R.; Hancher, M.; Turubanova, S.A.; Tyukavina, A.; Thau, D.; Stehman, S.V.; Goetz, S.J.; Loveland, T.R.; et al. High-resolution global maps of 21st-century forest cover change. Science 2013, 342, 850-853. [CrossRef] 
37. Chen, J.; Chen, J.; Liao, A.; Cao, X.; Chen, L.; Chen, X.; He, C.; Han, G.; Peng, S.; Lu, M.; et al. Global land cover mapping at 30m resolution: A POK-based operational approach. ISPRS J. Photogramm. Remote Sens. 2015, 103, 7-27. [CrossRef]

38. Gong, P.; Wang, J.; Yu, L.; Zhao, Y.; Zhao, Y.; Liang, L.; Niu, Z.; Huang, X.; Fu, H.; Liu, S.; et al. Finer resolution observation and monitoring of global land cover: First mapping results with landsat TM and ETM+ data. Int. J. Remote Sens. 2012, 34, 2607-2654. [CrossRef]

39. Li, C.; Gong, P.; Wang, J.; Zhu, Z.; Biging, G.S.; Yuan, C.; Hu, T.; Zhang, H.; Wang, Q.; Li, X.; et al. The first all-season sample set for mapping global land cover with landsat-8 data. Sci. Bull. 2017, 62, 508-515. [CrossRef]

40. Oliphant, A.; Thenkabail, P.; Teluguntla, P.; Xiong, J.; Congalton, R.; Yadav, K.; Smith, C. NASA Making Earth System Data Records for Use in Research Environments (MEaSUREs) Global Food Security-Support Analysis Data (GFSAD) Cropland Extent 2015. Southeast Asia 30 m V001; ICRISAT: Hyderabad, India, 2017. Available online: http://oar.icrisat.org/id/eprint/10981 (accessed on 20 November 2020).

41. Foody, G.M.; Mathur, A. Toward intelligent training of supervised image classifications: Directing training data acquisition for SVM classification. Remote Sens. Environ. 2004, 93, 107-117. [CrossRef]

42. Prasad, A.M.; Iverson, L.R.; Liaw, A. Newer classification and regression tree techniques: Bagging and random forests for ecological prediction. Ecosystems 2006, 9, 181-199. [CrossRef]

43. Richards, J.A.; Richards, J. Remote Sensing Digital Image Analysis; Springer: Berlin/Heidelberg, Germany, 1999 ; Volume 3.

44. Breiman, L. Random Forests. Mach. Learn. 2001, 45, 5-32. [CrossRef]

45. Naghibi, S.A.; Pourghasemi, H.R.; Dixon, B. GIS-based groundwater potential mapping using boosted regression tree, classification and regression tree, and random forest machine learning models in Iran. Environ. Monit. Assess. 2016, 188, 1-27. [CrossRef] [PubMed]

46. Shabani, S.; Jaafari, A.; Bettinger, P. Spatial modeling of forest stand susceptibility to logging operations. Environ. Impact Assess. Rev. 2021, 89, 106601. [CrossRef]

47. Abdullah, A.Y.M.; Masrur, A.; Adnan, M.S.G.; Baky, M.; Al, A.; Hassan, Q.K.; Dewan, A. Spatio-temporal patterns of land use/land cover change in the heterogeneous coastal region of Bangladesh between 1990 and 2017. Remote Sens. 2019, 11, 790. [CrossRef]

48. DeFries, R.S.; Townshend, J.R.G. NDVI-derived land cover classifications at a global scale. Int. J. Remote Sens. 1994, 15, 3567-3586. [CrossRef]

49. Gao, B.-C. NDWI-A normalized difference water index for remote sensing of vegetation liquid water from space. Remote Sens. Environ. 1996, 58, 257-266. [CrossRef]

50. Xiong, J.; Thenkabail, P.S.; Tilton, J.C.; Gumma, M.K.; Teluguntla, P.; Oliphant, A.; Congalton, R.G.; Yadav, K.; Gorelick, N. Nominal 30-m cropland extent map of continental Africa by integrating pixel-based and object-based algorithms using sentinel-2 and landsat-8 data on Google Earth Engine. Remote Sens. 2017, 9, 1065. [CrossRef]

51. Oad, V.K.; Mustafa, M.R.U.; Takaijudin, H.B.; Nabi, G.; Hussain, M. Monitoring trends of land use and land cover changes in rajang river basin. In Proceedings of the 2020 Second International Sustainability and Resilience Conference: Technology and Innovation in Building Designs(51154), Sakheer, Bahrain, 11-12 November 2020; Institute of Electrical and Electronics Engineers (IEEE): Piscataway, NJ, USA, 2020; Volume 51154, pp. 1-8. [CrossRef]

52. Lu, D.; Li, G.; Moran, E.; Hetrick, S. Spatiotemporal analysis of land-use and land-cover change in the Brazilian Amazon. Int. J. Remote Sens. 2013, 34, 5953-5978. [CrossRef]

53. Tian, Y.; Yin, K.; Lu, D.; Hua, L.; Zhao, Q.; Wen, M. Examining land use and land cover spatiotemporal change and driving forces in Beijing from 1978 to 2010. Remote Sens. 2014, 6, 10593-10611. [CrossRef]

54. Ghosh, A.; Sharma, R.; Joshi, P. Random forest classification of urban landscape using landsat archive and ancillary data: Combining seasonal maps with decision level fusion. Appl. Geogr. 2014, 48, 31-41. [CrossRef]

55. Liu, D.; Chen, N.; Zhang, X.; Wang, C.; Du, W. Annual large-scale urban land mapping based on landsat time series in Google Earth Engine and OpenStreetMap data: A case study in the middle Yangtze River basin. ISPRS J. Photogramm. Remote Sens. 2020, 159, 337-351. [CrossRef]

56. Bock, G.-W.; Zmud, R.W.; Kim, Y.-G.; Lee, J.-N. Behavioral intention formation in knowledge sharing: Examining the roles of extrinsic motivators, social-psychological forces, and organizational climate. MIS Q. 2005, 29, 87-111. [CrossRef]

57. Fielding, A.H.; Bell, J.F. A review of methods for the assessment of prediction errors in conservation presence/absence models. Environ. Conserv. 1997, 24, 38-49. [CrossRef]

58. Statistics Korea. Major Statistics Indicators of North Korea; Statistics Korea: Daejeon, Korea, 2019.

59. National Institute of Forest Science. Development of a Method of Constructing North Korean Forest Information Using Satellite Imagery and AI; National Institute of Forest Science: Seoul, Korea, 2020. (In Korean)

60. CRED. Annual Disaster Statistical Review 2015; CRED: Bengaluru, India, 2016.

61. Han, S.H. Statistics on Livestock and Fishery Products in North Korea; Agricultural Village Research Institute: Ansan, Korea, 2017. (In Korean)

62. Park, K.; Lee, S.; Park, S. A study on the North Korea's change of forest policy since the economic crisis in 1990s. Korean J. Unification Aff. 2009, 21, 459-492.

63. Oh, S.; Kim, E.; Kim, K. Characteristics of forest policy in the Kim Jong-Un era. North Korean Stud. 2018, 14, 101-133. 
64. Yu, J.; Park, H.; Kim, K.; Lee, S.-H. Review of slope criteria and forestland restoration plan in North Korea. J. Korea Soc. Environ. Restor. Technol. 2016, 19, 19-28. [CrossRef]

65. Lee, S. North Korean Industrial Statistics; KIET: Sejong, Korea, 2015. (In Korean)

66. Lee, B.-R.; Oh, S.-B.; Byun, H.-R. The characteristics of drought occurrence in North Korea and its comparison with drought in South Korea. Theor. Appl. Clim. 2015, 121, 199-209. [CrossRef]

67. Ryu, J.-H.; Han, K.-S.; Lee, Y.-W.; Park, N.-W.; Hong, S.; Chung, C.-Y.; Cho, J. Different agricultural responses to extreme drought events in neighboring counties of South and North Korea. Remote Sens. 2019, 11, 1773. [CrossRef]

68. Kim, K.-H.; Choi, K.-W.; Kim, I.-S.; Noh, S.-I. North Korea's agricultural irrigation system. J. Korean Soc. Agric. Eng. 2014, 2014, 129.

69. Kim, K.-H.; Jin, W.-G. Water resources of North Korea. J. Korean Soc. Agric. Eng. 2013, 102.

70. Lee, S. North Korea's Industry Trends in 2017; [KDI] North Korean Economy [Review, 20]; KIET: Sejong, Korea, 2018. (In Korean)

71. Daunt, A.B.P.; Silva, T.S.F. Beyond the park and city dichotomy: Land use and land cover change in the northern coast of São Paulo (Brazil). Landsc. Urban Plan. 2019, 189, 352-361. [CrossRef]

72. Lone, S.; Mayer, I.A. Geo-spatial analysis of land use/land cover change and its impact on the food security in District Anantnag of Kashmir Valley. GeoJournal 2018, 84, 785-794. [CrossRef]

73. Kim, E.-S.; Lee, S.-H.; Cho, H.-K. Segment-based land cover classification using texture information in degraded forest land of north korea. Korean J. Remote Sens. 2010, 26, 477-487.

74. Song, X.-P.; Hansen, M.C.; Stehman, S.V.; Potapov, P.V.; Tyukavina, A.; Vermote, E.F.; Townshend, J.R. Global land change from 1982 to 2016. Nature 2018, 560, 639-643. [CrossRef] [PubMed]

75. Muriithi, F.K. Land use and land cover (LULC) changes in semi-arid sub-watersheds of Laikipia and Athi River basins, Kenya, as influenced by expanding intensive commercial horticulture. Remote Sens. Appl. Soc. Environ. 2016, 3, 73-88. [CrossRef]

76. Kleemann, J.; Baysal, G.; Bulley, H.N.; Fürst, C. Assessing driving forces of land use and land cover change by a mixed-method approach in north-eastern Ghana, West Africa. J. Environ. Manag. 2017, 196, 411-442. [CrossRef] [PubMed] 